\title{
Efficacy and safety of sunitinib in elderly patients with advanced renal cell carcinoma
}

\author{
TETSUO FUJITA, TAKAHIRO HIRAYAMA, DAISUKE ISHII, KAZUMASA MATSUMOTO, \\ KAZUNARI YOSHIDA and MASATSUGU IWAMURA
}

Department of Urology, Kitasato University School of Medicine, Sagamihara, Kanagawa 252-0374, Japan

Received January 13, 2018; Accepted June 25, 2018

DOI: $10.3892 / \mathrm{mco} .2018 .1684$

\begin{abstract}
Elderly individuals represent a consistent proportion of all cancer patients. However, they are under-represented in clinical trials. The present study evaluated the actual tolerability of sunitinib in elderly Japanese patients with advanced renal cell carcinoma (RCC). A total of 56 consecutive patients with advanced RCC treated with sunitinib were enrolled. Patients were divided into two groups according to their age at the time of sunitinib initiation: i) elderly cohort ( $\geq 70$ years); and ii) younger cohort ( $<70$ years). Disease control rate, progression-free survival, overall survival and relative dose intensity (RDI) were compared between the two cohorts. The elderly cohort comprised of 14 patients $(25.0 \%)$, and the younger cohort included 42 patients $(75.0 \%)$. The elderly cohort had a significantly higher Charlson comorbidity index than the younger cohort (mean, 9.7 vs. 7.9; $\mathrm{P}<0.0001$ ). Disease control rate, progression-free survival, and overall survival were not significantly different. The elderly cohort had a significantly lower RDI than the younger cohort (mean, 51.7 vs. $65.0 \%$; $\mathrm{P}=0.0340$ ). Thus, treatment with sunitinib is feasible and effective in elderly Japanese patients with advanced RCC. However, the RDI of elderly patients was significantly lower, and a relatively low dose of sunitinib provided optimal therapeutic efficacy.
\end{abstract}

\section{Introduction}

Sunitinib malate (Sutent, Pfizer Inc., New York, NY, USA), a small-molecule multi-targeted inhibitor of tyrosine kinases, is widely recognized as a standard treatment option for patients with advanced renal cell carcinoma (RCC). In a randomized, multicenter,phase IIItrial,750 patients with previously untreated metastatic RCC were enrolled to receive either sunitinib or interferon $\alpha$ (IFN- $\alpha$ ). Sunitinib was found to be superior to

Correspondence to: Dr Tetsuo Fujita, Department of Urology, Kitasato University School of Medicine, 1-15-1 Kitasato, Sagamihara, Kanagawa 252-0374, Japan

E-mail: tfujita@cd5.so-net.ne.jp

Key words: renal cell carcinoma, sunitinib, elderly
IFN- $\alpha$ with respect to objective response rate (47 vs. $12 \%$ ), progression-free survival (median, 11.0 vs. 5.0 months), and overall survival (median, 26.4 vs. 21.8 months) $(1,2)$.

Elderly patients constitute a large proportion of the advanced RCC population, and the incidence of RCC peaks between ages 60 and 70 years (3). Overall survival in RCC patients is negatively correlated with the severity and number of comorbidities (4). Comorbid conditions are generally more prevalent in elderly patients compared with younger patients $(5,6)$. In addition, elderly patients with cancer are more likely to have a compromised performance status (PS) (7). The presence of comorbidities and decreased PS in elderly patients may result in their under-representation in clinical trials $(8,9)$. Clinical trials have not directly compared the efficacy and safety of targeted agents in the elderly population, and outcomes in elderly subsets may be informative about how age affects the efficacy and tolerability of individual targeted agents. In the present study, we evaluate the actual tolerability of sunitinib in elderly Japanese patients with advanced RCC.

\section{Patients and methods}

The present study was performed with the approval of the Kitasato University Medical Ethics Organization (approval no. KMEO B16-156); the requirement for informed consent was waived due to the retrospective nature of the analyses. The data of 56 consecutive patients with advanced RCC who underwent sunitinib treatment between December 2008 and December 2012 was collected and analyzed in the present study. Eligible patients had measurable tumors (metastatic or primary). All patients had undergone surgical treatment or biopsy of the primary lesion and had histologically proven RCC. The sample comprised 40 men and 16 women with a median age of 64 years (range, 36-80 years) at the time of sunitinib initiation. In general, $50 \mathrm{mg}$ sunitinib was administered orally once daily in a 6-week cycle consisting of 4 weeks of treatment followed by 2 weeks without treatment. Dose reductions were permitted on the basis of individual tolerability.

Response and progression were assessed by the treating physician according to the Response Evaluation Criteria in Solid Tumors (RECIST), version 1.1, with computed tomography or magnetic resonance imaging performed every 4 to 8 weeks. Adverse events were evaluated by means of physical examination and laboratory assessments such as 
hematologic and serum chemistry every 2 to 4 weeks during treatment with sunitinib and were graded according to the National Cancer Institute Common Terminology Criteria for Adverse Events (NCI CTCAE), version 4.0.

Patient charts were retrospectively reviewed. Patients were divided into two groups according to the age at the time of sunitinib initiation: (i) elderly cohort ( $\geq 70$ years), and (ii) younger cohort ( $<70$ years). Comorbidity in each patient was evaluated by the Charlson comorbidity index (10). Disease control rates, which were defined as complete response, partial response, and stable disease, were evaluated. Progression-free survival, overall survival, and relative dose intensity (RDI) were analyzed for each cohort. The RDI was determined as the ratio of the cumulative dose that was received during the cycle to $1,400 \mathrm{mg}$.

The groups were analyzed using the t-test for differences of means between groups. The chi-square test was used to evaluate differences for categorical variables. Non-parametric estimates of survival were performed using Kaplan-Meier curves. Survival curves were generated on the basis of progression-free survival or overall survival from the initiation of sunitinib to the date of disease progression or death. Log-rank tests were used for statistical comparisons. All analyses were performed with StatView, version 5.0 (SAS Institute, Cary, $\mathrm{NC}$, USA), and $\mathrm{P}<0.05$ was considered to indicate a statistically significant difference.

\section{Results}

The clinical characteristics of each cohort treated with sunitinib are summarized in Table I. The elderly cohort ( $\geq 70$ years; range, 71-80 years) comprised 10 men and 4 women (total 14 patients; $25.0 \%$ ). The younger cohort ( $<70$ years; range, 36-69 years) comprised 30 men and 12 women (total 42 patients; $75.0 \%$ ). The elderly cohort had a significantly higher Charlson comorbidity index than the younger cohort (mean, 9.7 vs. 7.9; $\mathrm{P}<0.0001$ ). Other pretreatment variables, including Eastern Cooperative Oncology Group PS, Memorial Sloan-Kettering Cancer Center risk classification, C-reactive protein, prior nephrectomy, prior immunotherapy, prior targeted therapy, and number of metastatic sites, did not reach statistically significant differences (Table I).

Disease control rates according to the RECIST were $57.1 \%$ in both cohorts. The median progression-free survival time was 8.0 months in the elderly cohort and 12.0 months in the younger cohort (Fig. 1). The median overall survival time was 15.0 months in the elderly cohort and 20.0 months in the younger cohort (Fig. 2). The differences did not reach statistical significance.

Starting doses of sunitinib were not significantly different between the elderly and younger cohorts $(\mathrm{P}=0.4838)$. In the elderly cohort, the starting dose was $50 \mathrm{mg}$ in 2 patients $(14.3 \%)$, $37.5 \mathrm{mg}$ in 8 patients (57.1\%), and $25 \mathrm{mg}$ in 4 patients (28.6\%). In the younger cohort, the starting dose was $50 \mathrm{mg}$ in 10 patients (23.8\%), $37.5 \mathrm{mg}$ in 17 patients (40.5\%), $25 \mathrm{mg}$ in 11 patients (26.2\%), and $12.5 \mathrm{mg}$ in 4 patients $(9.5 \%)$. Dose reductions were needed for all patients in the elderly cohort and $90.5 \%$ of the patients in the younger cohort. The elderly cohort had a significantly lower RDI than the younger cohort (mean \pm standard deviation, $51.7 \pm 19.0 \%$ vs. $65.0 \pm 20.2 \%$; $\mathrm{P}=0.0340$, Fig. 3 ).
Table I. Patient characteristics grouped by age at the time of sunitinib initiation.

\begin{tabular}{lccc}
\hline Characteristics & $\geq 70$ years & $<70$ years & P-value \\
\hline Total patients, n (\%) & $14(25.0)$ & $42(75.0)$ & - \\
Age, years & $71-80$ & $36-69$ & - \\
Sex, n (\%) & & & - \\
Male & $10(71.4)$ & $30(71.4)$ & \\
Female & $4(28.6)$ & $12(28.6)$ &
\end{tabular}

Charlson comorbidity $<0.0001$

index

$\begin{array}{lcc}\text { Median } & 9 & 8 \\ \text { Range } & 9-11 & 6-10 \\ \text { Mean } & 9.7 & 7.9 \\ \text { ECOG PS } & & \\ 0 & 10(71.4) & 27(64.3) \\ \geq 1 & 4(28.6) & 15(35.7)\end{array}$

MSKCC risk

classification, n (\%)

Favorable

$3(21.4) \quad 7(16.7)$

Intermediate

$8(57.1) \quad 21(50.0)$

Poor

Pretreatment CRP, n $(\%)$

$\leq 0.30 \mathrm{mg} / \mathrm{dl}$

$3(21.4)$

$>0.30 \mathrm{mg} / \mathrm{dl}$

$6(42.9) \quad 11(26.2)$

$8(57.1) \quad 31(73.8)$

Prior nephrectomy, n (\%)

Yes

$13(92.9) \quad 31(73.8)$

No

$1(7.1) \quad 11(26.2)$

Histological

classification, n (\%)

Clear-cell

$14(100) \quad 39(92.9)$

Papillary

0 (0)

T stage, n (\%)

$\mathrm{T} 1$ or $\mathrm{T} 2$

$8(57.1)$

$\geq \mathrm{T} 3$

$6(42.9)$

Grade, n (\%)

1 or 2

3

$10(71.4) \quad 23(54.8)$

2 (14.3) 14 (33.3)

Prior immunotherapy, $\mathrm{n}$

IFN- $\alpha$

6

IL- 2 and IFN- $\alpha$

Prior targeted therapy, $\mathrm{n}$

Sorafenib

Metastatic sites, $\mathrm{n}$

Lung

Bone

Lymph nodes

Brain

Pancreas

Adrenal

Skin

Liver

Kidney

Local

Prostate
$14(33.3)$

0.2402

$3(7.1)$

$17(40.5)$

$25(59.5)$

11

8

4

0.8667

0.6249

0.3040

0.2773

0.4401

8

13

31

15

11

4

4

4

3

3

2

2 
Table I. Continued.

\begin{tabular}{llll}
\hline Characteristics & $\geq 70$ years & $<70$ years & P-value \\
\hline $\begin{array}{l}\text { No. of metastatic sites, } \\
\mathrm{n}(\%)\end{array}$ & & 0.9410 \\
1 & $5(35.7)$ & $17(40.5)$ & \\
$\geq 2$ & $7(50.0)$ & $25(59.5)$ & \\
Treatment, n (\%) & & & 0.3887 \\
First-line & $5(35.7)$ & $21(50.0)$ & \\
Second-line & $6(42.9)$ & $10(23.8)$ & \\
Third-line & $3(21.4)$ & $11(26.2)$ & \\
\hline
\end{tabular}

ECOG, Eastern Cooperative Oncology Group, PS, performance status, MSKCC, Memorial Sloan-Kettering Cancer Center, CRP, C-reactive protein, IFN- $\alpha$, interferon $\alpha$, IL-2, interleukin-2.

Selected treatment-related adverse events that occurred during the study are summarized in Table II. The elderly cohort demonstrated significantly lower frequency of altered taste than the younger cohort $(\mathrm{P}=0.0383)$. No other adverse events showed statistically significant differences. In addition, there were no NCI CTCAE grade 4 or 5 adverse events in either cohort. No patients discontinued sunitinib treatment because of adverse events.

\section{Discussion}

This retrospective study demonstrated that sunitinib efficacy and safety are comparable between elderly and younger Japanese patients with advanced RCC. Disease control rates, progression-free survival times, and overall survival times were not significantly different between the elderly and younger cohorts. Previous studies revealed similar efficacy and tolerability of sunitinib in patients aged $\geq 70$ years $(11,12)$. Brunello et al (11) reported that median progression-free survival was 13.6 months and median overall survival was 18.3 months in 68 elderly Italian patients with metastatic RCC treated with sunitinib. They concluded that treatment with sunitinib is feasible and effective in elderly patients (11). Hutson et al (12) reported a large pooled data set from six clinical trials. Of 1,059 patients with metastatic RCC treated with sunitinib, $202(19 \%)$ were $\geq 70$ years. In the first-line treatment setting, median progression-free survival was 11.0 months and median overall survival was 25.6 months. In the cytokine-refractory treatment setting, median progression-free survival was 8.4 months and overall survival was 15.8 months. The adverse events profile was broadly similar in elderly and younger patients. Advanced age alone should not be a deterrent to using sunitinib in this population (12).

Despite comparable results in survival analysis in the current study, sunitinib doses were different. RDI (mean \pm standard deviation) was $51.7 \pm 19.0 \%$ for the elderly cohort and $65.0 \pm 20.2 \%$ for the younger cohort. The elderly cohort had a significantly lower RDI than the younger cohort $(\mathrm{P}=0.0340)$. The significantly lower RDI of sunitinib is a novel finding from the present study. Elderly Japanese patients obtained optimal therapeutic efficacy from a relatively low dose of sunitinib. In contrast to this result, Hutson et al (12) reported that exposure to sunitinib was comparable in elderly and younger age groups. In their study, the median RDI of sunitinib was $89.7 \%$ for patients aged $\geq 70$ years and $97.1 \%$ for patients aged $<70$ years (12). In addition, an expanded-access trial reported that mean RDI was $95.2 \%$ (13). However, difficulty continuing an initial dose of sunitinib therapy without drug withdrawal has been reported in Japanese patients (14). Thus, genetic differences in sunitinib metabolism should be considered.

The adverse events profiles are comparable between elderly and younger patients in this study, higher incidence of adverse events than phase III clinical trial (1) was observed. Hutson et al (12) already published large pooled data sets of sunitinib-treated patients with RCC and have shown that the adverse events profiles are similarly in elderly and younger patients. Kato et al (15) reported a high incidence of sunitinib-induced hematotoxicity in Japanese patients with RCC, resulting in difficulties maintaining the original 4-weeks on 2 -weeks off dosing regimen because of a high incidence of adverse events. There are no established criteria to decide the starting and maintenance doses in molecular-targeted agents (15). Modified dosing regimen should be designed especially for elderly patients with advanced RCC.

Elderly patients with RCC may be more responsive to sunitinib treatment. A recent RCC tumor biopsy study revealed age-related differences in tumor vasculature, with clear cell RCC tumors from patients aged $\geq 65$ years having significantly higher microvascular density than those from patients aged $<65$ years; in addition, markers of angiogenic activity also differed (16). Potential explanations for the elderly being more responsive to sunitinib are that the higher microvascular density results in greater sensitivity to anti-angiogenic treatment or that the higher vessel density is inversely associated with tumor aggressiveness (17).

Several studies have suggested that increasing age is an adverse prognostic factor in RCC, with older age being associated with higher tumor stage and grade (18-21). However, efficacy and safety of sunitinib were comparable between elderly and younger patients with advanced RCC. The lack of clinical trial data and the associated dearth of evidence-based guidelines for elderly patients mean that physicians have little to guide them, with the result that patients may not receive the optimal therapy (22). Characterizing the efficacy and safety of sunitinib treatment in elderly patients is important.

The potential limitations of this study are that it was a retrospective single institutional study and the sample size was small. The major drawback of this study is the small patient numbers, which makes it unlikely to expect differences that reach statistical relevance. From the only 14 'elderly' patients, 8 patients are in tumor stage T1 or $\mathrm{T} 2$ and 6 patients are in $\geq \mathrm{T} 3$. One patient did not undergo surgery prior treatment, meaning, the elderly cohort is inhomogeneously. In a post-marketing Japanese study of sunitinib including 1,689 patients with advanced RCC, $43 \%$ of patients were $\geq 65$ years and the maximum age was 88 years old. This real-world analysis revealed that median progression-free survival was 22.7 weeks and median overall survival was not reached (23). These limitations are unlikely to have affected the validity of our results. 
Table II. Selected treatment-associated adverse events (all grades).

\begin{tabular}{|c|c|c|c|}
\hline Event & $\geq 70$ years & 70 years & P-value \\
\hline \multicolumn{4}{|l|}{ Adverse event, $\%$} \\
\hline Hypertension & 64.3 & 61.9 & 0.8734 \\
\hline Hand-foot syndrome & 35.7 & 47.6 & 0.4378 \\
\hline Stomatitis & 57.1 & 40.5 & 0.2773 \\
\hline Fatigue & 35.7 & 40.5 & 0.7520 \\
\hline Diarrhea & 42.9 & 38.1 & 0.7520 \\
\hline Altered taste & 14.3 & 45.2 & 0.0383 \\
\hline Edema & 35.7 & 23.8 & 0.3837 \\
\hline Nausea & 14.3 & 9.5 & 0.6179 \\
\hline Fever & 14.3 & 9.5 & 0.6179 \\
\hline Cardiac dysfunction & 7.1 & 4.8 & 0.7319 \\
\hline Cholecystitis & 0 & 7.1 & 0.3040 \\
\hline Enteritis & 0 & 2.4 & 0.5602 \\
\hline Nasal bleeding & 0 & 2.4 & 0.5602 \\
\hline \multicolumn{4}{|l|}{ Laboratory abnormalities, $\%$} \\
\hline Leukopenia & 85.7 & 83.3 & 0.8336 \\
\hline Anemia & 85.7 & 76.2 & 0.4520 \\
\hline Thrombocytopenia & 92.9 & 92.9 & - \\
\hline Increased creatinine & 50.0 & 45.2 & 0.7570 \\
\hline Increased alanine transaminase & 14.3 & 9.5 & 0.6179 \\
\hline Increased alkaline phosphatase & 0 & 4.8 & 0.4057 \\
\hline Increased lipase & 0 & 9.5 & 0.2308 \\
\hline Hypothyroidism & 50.0 & 64.3 & 0.3432 \\
\hline Proteinuria & 64.3 & 78.6 & 0.2850 \\
\hline
\end{tabular}

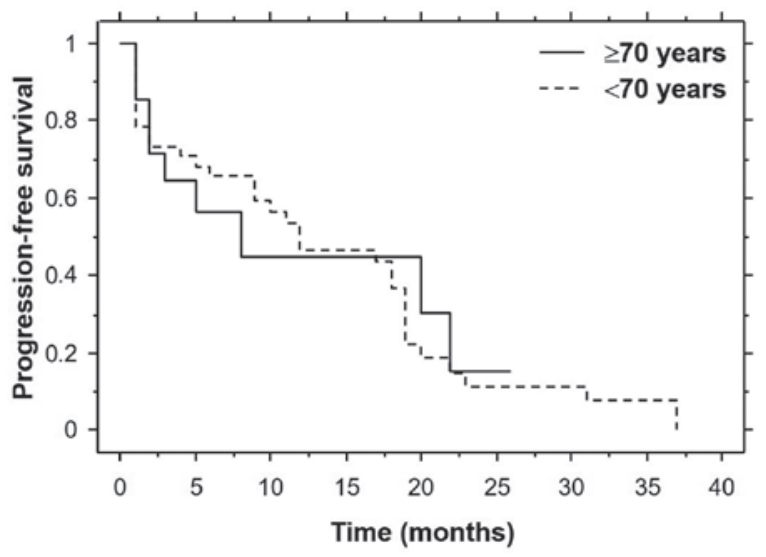

Figure 1. Kaplan-Meier progression-free survival of the elderly and younger cohorts. No statistically significant differences were identified (log-rank $\mathrm{P}=0.9767)$.

Although the elderly cohort ( $\geq 70$ years) had a significantly lower RDI, relatively shorter progression-free and overall survival times than the younger cohort ( $<70$ years), clinical benefit might be obtained from sunitinib treatment.

In conclusion, treatment with sunitinib is feasible and effective in elderly Japanese patients. However, the RDI of elderly patients is significantly lower than that of younger patients. The current sunitinib dosing schedule is likely not optimal for

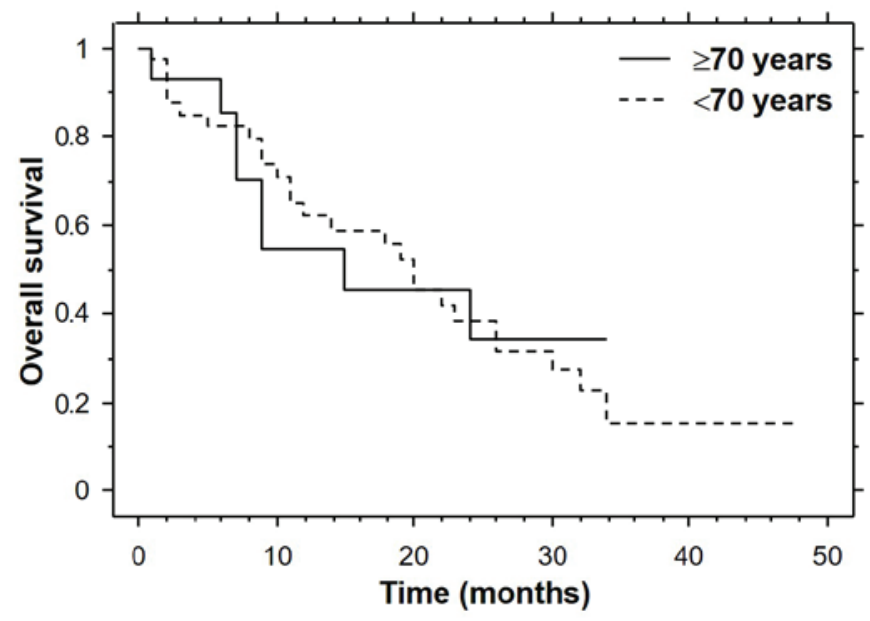

Figure 2. Kaplan-Meier overall survival of the elderly and younger cohorts. No statistically significant differences were observed (log-rank P=0.9356).

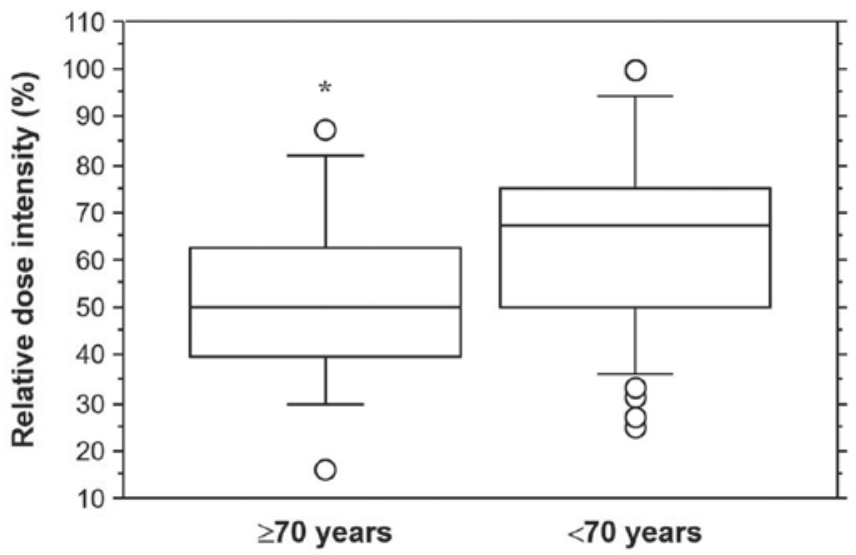

Figure 3. Relative dose intensity of the elderly and younger cohorts. The elderly cohort exhibited a significantly lower relative dose intensity compared with the younger cohort $(\mathrm{P}=0.0340)$. ${ }^{*} \mathrm{P}<0.05$ vs. $<70$ years.

elderly patients and most of them may be over-treated. Starting sunitinib treatment at a reduced dose should be considered for elderly patients with advanced RCC.

\section{Acknowledgements}

The authors would like to thank Dr Neil M. Singer for providing expert editorial assistance.

\section{Funding}

No funding was received.

\section{Availability of data and materials}

The datasets used and/or analyzed during the current study are available from the corresponding author on reasonable request.

\section{Author's contributions}

TF designed the present study. TH, DI, KY and MI collected and interpreted the patients' data. TF and KM analyzed the 
patients' data. TF was a major contributor in writing the manuscript. All authors read and approved the final manuscript.

\section{Ethics approval and consent to participate}

The present study was approved by the Kitasato University Medical Ethics Organization (approval no: KMEO B16-156). Patient written informed consent was not required for the present study as it was conducted retrospectively.

\section{Patient consent for publication}

Not applicable.

\section{Competing interests}

The authors declare that they have no competing interests.

\section{References}

1. Motzer RJ, Hutson TE, Tomczak P, Michaelson MD, Bukowski RM, Rixe O, Oudard S, Negrier S, Szczylik C, Kim ST, et al: Sunitinib versus interferon alfa in metastatic renal-cell carcinoma. N Engl J Med 356: 115-124, 2007.

2. Motzer RJ, Hutson TE, Tomczak P, Michaelson MD, Bukowski RM, Oudard S, Negrier S, Szczylik C, Pili R, Bjarnason GA, et al: Overall survival and updated results for sunitinib compared with interferon alfa in patients with metastatic renal cell carcinoma. J Clin Oncol 27: 3584-3590, 2009.

3. Ljungberg B, Bensalah K, Canfield S, Dabestani S, Hofmann F, Hora M, Kuczyk MA, Lam T, Marconi L, Merseburger AS, et al: EAU guidelines on renal cell carcinoma: 2014 update. Eur Urol 67: 913-924, 2015.

4. Berger DA, Megwalu II, Vlahiotis A, Radwan MH, Serrano MF, Humphrey PA, Piccirillo JF and Kibel AS: Impact of comorbidity on overall survival in patients surgically treated for renal cell carcinoma. Urology 72: 359-363, 2008.

5. Coebergh JW, Janssen-Heijnen ML, Post PN and Razenberg PP: Serious co-morbidity among unselected cancer patients newly diagnosed in the southeastern part of The Netherlands in 1993-1996. J Clin Epidemiol 52: 1131-1136, 1999.

6. Coebergh JW, Janssen-Heijnen ML and Razenberg PP: Prevalence of co-morbidity in newly diagnosed patients with cancer: A population-based study. Crit Rev Oncol Hematol 27: 97-100, 1998

7. Repetto L, Venturino A, Vercelli M, Gianni W, Biancardi V, Casella C, Granetto C, Parodi S, Rosso R and Marigliano V: Performance status and comorbidity in elderly cancer patients compared with young patients with neoplasia and elderly patients without neoplastic conditions. Cancer 82: 760-765, 1998.

8. Lewis JH, Kilgore ML, Goldman DP, Trimble EL, Kaplan R, Montello MJ, Housman MG and Escarce JJ: Participation of patients 65 years of age or older in cancer clinical trials. J Clin Oncol 21: 1383-1389, 2003.

9. Surbone A: Ethical considerations in conducting clinical trials for elderly cancer patients. Aging Health 4: 253-260, 2008.
10. Charlson ME, Pompei P, Ales KL and MacKenzie CR: A new method of classifying prognostic comorbidity in longitudinal studies: Development and validation. J Chronic Dis 40: 373-383, 1987.

11. Brunello A, Basso U, Sacco C, Sava T, De Vivo R, Camerini A, Barile C, Roma A, Maruzzo M, Falci C, et al: Safety and activity of sunitinib in elderly patients ( $\geq 70$ years) with metastatic renal cell carcinoma: A multicenter study. Ann Oncol 24: 336-342, 2013.

12. Hutson TE, Bukowski RM, Rini BI, Gore ME, Larkin JM, Figlin RA, Barrios CH, Escudier B, Lin X, Fly K, et al: Efficacy and safety of sunitinib in elderly patients with metastatic renal cell carcinoma. Br J Cancer 110: 1125-1132, 2014.

13. Gore ME, Szczylik C, Porta C, Bracarda S, Bjarnason GA, Oudard S, Hariharan S, Lee SH, Haanen J, Castellano D, et al: Safety and efficacy of sunitinib for metastatic renal-cell carcinoma: An expanded-access trial. Lancet Oncol 10: 757-763, 2009.

14. Kawashima A, Tsujimura A, Takayama H, Arai Y, Nin M, Tanigawa G, Yasunaga Y, Mukai M, Uemura M, Nakai Y, et al; Osaka Renal Cell Carcinoma Clinical Study Collaboration: Importance of continuing therapy and maintaining one-month relative dose intensity in sunitinib therapy for metastatic renal cell carcinoma. Med Oncol 29: 3298-3305, 2012.

15. Kato R, Kato Y, Matsuura T, Kanehira M, Takata R and Obara W: Characteristics of early-onset hematotoxicity of sunitinib in Japanese patients with renal cell carcinoma. BMC Cancer 17: 214, 2017.

16. Meehan B, Appu S, St Croix B, Rak-Poznanska K, Klotz L and Rak J: Age-related properties of the tumour vasculature in renal cell carcinoma. BJU Int 107: 416-424, 2011.

17. Yildiz E, Ayan S, Goze F, Gokce G and Gultekin EY: Relation of microvessel density with microvascular invasion, metastasis and prognosis in renal cell carcinoma. BJU Int 101: 758-764, 2008.

18. Denzinger S, Otto W, Burger M, Hammerschmied C, Junker K, Hartmann A, Wieland WF and Walter B: Sporadic renal cell carcinoma in young and elderly patients: Are there different clinicopathological features and disease specific survival rates? World J Surg Oncol 5: 16, 2007.

19. Verhoest G, Veillard D, Guillé F, De La Taille A, Salomon L, Abbou CC, Valéri A, Lechevallier E, Descotes JL, Lang H, et al: Relationship between age at diagnosis and clinicopathologic features of renal cell carcinoma. Eur Urol 51: 1298-1304, discussion 1304-1305, 2007.

20. Karakiewicz PI, Jeldres C, Suardi N, Hutterer GC, Perrotte P, Capitanio U, Ficarra V, Cindolo L, de La Taille A, Tostain J, et al: Age at diagnosis is a determinant factor of renal cell carcinomaspecific survival in patients treated with nephrectomy. Can Urol Assoc J 2: 610-617, 2008.

21. Jung EJ, Lee HJ, Kwak C, Ku JH and Moon KC: Young age is independent prognostic factor for cancer-specific survival of low-stage clear cell renal cell carcinoma. Urology 73: 137-141, 2009.

22. Aapro MS, Köhne CH, Cohen HJ and Extermann M: Never too old? Age should not be a barrier to enrollment in cancer clinical trials. Oncologist 10: 198-204, 2005.

23. Akaza H, Naito S, Ueno N, Aoki K, Houzawa H, Pitman Lowenthal S and Lee SY: Real-world use of sunitinib in Japanese patients with advanced renal cell carcinoma: Efficacy, safety and biomarker analyses in 1689 consecutive patients. Jpn J Clin Oncol 45: 576-583, 2015. 